\title{
Fast and In-Situ Identification of Archaeometallurgical Collections in the Museum of Malaga Using Laser- Induced Breakdown Spectroscopy and a New Mathematical Algorithm
}

\author{
Francisco J. Fortes $+\left(\mathbb{D}\right.$, Luisa M. Cabalín $+\mathbb{D}$ and Javier J. Laserna $*++^{(\mathbb{D}}$ \\ UMALASERLAB, Departamento de Química Analítica, Universidad de Málaga, \\ C/Jiménez Fraud 4, 29010 Malaga, Spain; javierfortes@uma.es (F.J.F.); lmcabalin@uma.es (L.M.C.) \\ * Correspondence: laserna@uma.es; Tel.: +34-951953007 \\ + These authors contributed equally to this work.
}

Received: 2 October 2020; Accepted: 6 November 2020; Published: 10 November 2020

check for updates

\begin{abstract}
This paper reports the use of an advanced statistical algorithm for the recognition and classification of a set of 30 archaeological metallic objects from the Museum of Malaga. In-situ laser-induced breakdown spectrometry (LIBS) analysis was performed using a portable analyzer. The coordinate-obtaining method provided the statistical weights of each element in the sample. A comparative study between the coordinate-obtaining method and the linear correlation method is also discussed in order to corroborate the applicability of the proposed approach to the field of cultural heritage. The possibility of fast identification based on the simultaneous comparison of all the spectra in the reference LIBS library while allowing the analysis of heterogeneous materials is the main advantage of the method. In addition, statistical analysis (Euclidean distance analysis and binary diagrams) suggested that differentiating between archaeological sites is feasible.
\end{abstract}

Keywords: laser-induced breakdown spectrometry; metallic objects; identification algorithm; archaeometallurgical

\section{Introduction}

The knowledge of archaeometallurgy is of great historical importance to study the technologies, origins, and progressive evolution of civilizations. The chemical information extracted from the raw materials used in ancient times and the technology employed in the production of archaeological objects are fundamental in the understanding of historic events [1]. Recently, the development of modern analytical methods has contributed to the growth of archaeology [2-5]. The most widely used techniques in the inspection, analysis, and dating of objects of heritage value include: scanning auger microscopy (SAM) [6], X-ray fluorescence (XRF) [7,8], X-ray photoelectron spectroscopy (XPS), inductively coupled plasma coupled to optical emission (ICP-OES) [9], X-ray diffraction (XRD), Raman microscopy, [3-9] nuclear magnetic resonance (NMR) [10,11], and X-ray computed tomography (XCT) [12-14]. The application of these methods in the cultural heritage field has provided information about the spatial distributions of elements, structures of materials, the origins of objects, their usage, and the levels of degradation in artworks. J. Kaiser et al. demonstrated the capability of high-resolution X-ray computed tomography (HRXCT) for the nondestructive 3D inspection of geological material, and they combined this technique with double-pulse laser-induced breakdown spectrometry (DP LIBS) with the objective of obtaining chemical maps of Platinum Group Element (PGE)-Cu-Ni sulfide deposits from Siberia [14]. 
Nowadays, laser-induced breakdown spectrometry (LIBS) is an established technique for surface analysis $[15,16]$. The capability of LIBS in terms of its speed, the lack of necessary preparation of the sample, and the possibility of performing in-situ analysis has been extensively demonstrated in the archeological and cultural heritage field [17-21]. Moreover, the development of portable systems gives greater flexibility and also increases the range of LIBS applications [21]. This approach has been employed in the elemental analysis of artworks located in museum, caves, historical building, or monuments [22,23]. Regarding the importance of the corrected preservation and protection of submerged cultural heritage, in-situ and stand-off LIBS technology for subsea analysis of archaeological and shipwreck objects has been also reported [24-27]. The performances of underwater analysis have been improved by using multi-pulse LIBS excitation [25]. The remote LIBS arrangement proposed by Fortes et al. was capable of inspecting a copper-based alloy located at depths of up $30 \mathrm{~m}$ under the Mediterranean Sea [26]. The same research group assessed this prototype in a marine environment in order to identify real shipwrecks and different submerged pieces, which were sorted by linear discrimination analysis (LDA) [24].

At present, the development of new methodologies for quantitative analysis has made possible a more detailed characterization and understanding of archaeological specimens. Calibration curves (CC) [28] and calibration-free (CF) methods based on the electron temperature calculated from the Saha-Boltzmann equation have usually been used for quantitative analysis of archaeological artifacts $[29,30]$. Other promising chemometric tools used for recognition and classification, such as soft independent modeling of class analogy (SIMCA), principal component analysis (PCA), and linear correlation, have been proposed [31-35]. Linear correlation (based on the comparison of LIBS spectra and calculation of correlation coefficients) in conventional and ranked ways has been employed for determining similarities and differences between LIBS spectra from Roman pottery $[34,35]$.

In this work, a mathematical algorithm named "coordinate obtaining method" for identifying samples in cultural heritage analysis was evaluated [36]. The coordinate-obtaining method is based on a linear algebra model to obtain the relation between the sample and a library of spectra. In this way, the spectrum coming from the sample is simultaneously compared with all the elements of a standard reference library. As a result, a normalized coordinate that indicates the statistical weight of each standard reference present in the sample is obtained. The advantage of this process with respect to other techniques for spectrum identification, such as linear and rank correlation, is the possibility to acquire semi-quantitative data of a mixture of specimens in the sample. The coordinate-obtaining method was applied to spectral data obtained by LIBS in order to obtain in-situ characterization of thirty archaeometallurgical artifacts in the Museum of Malaga. This mathematical approach is compared with a linear correlation method.

\section{Materials and Methods}

\subsection{Experimental Set-Up}

The portable LIBS instrument and its construction have been described elsewhere [23], so only a brief description of the field apparatus is given here. The LIBS system consists of (i) a hand-held probe that encloses the laser head, the focusing lens, and the fiber-optic cable, (ii) a main unit containing the spectrometer, a miniaturized PC motherboard, and electronics, and (iii) the laser power supply. These blocks can be easily split, permitting effortless separate transportation of the instrument. The main unit has an overall weight of approximately $5 \mathrm{~kg}$ and a size of $45 \times 27 \times 15 \mathrm{~cm}^{3}$.

Samples were irradiated using a Q-switched Nd:YAG laser (Ultra CFR Model, Big Sky Laser, MO, USA), operating at $1064 \mathrm{~nm}$ and generating pulses of $50 \mathrm{~mJ}$ and $6.5 \mathrm{~ns}$. The laser beam was focused onto the sample surface by an antireflection-coated BK7 planoconvex lens (diameter $=6.35 \mathrm{~mm}$, focal length $=75.6 \mathrm{~mm}$ ). The plasma light was directly collected by a fiber-optic cable ( $5 \mathrm{~m}$ length, $600 \mu \mathrm{m}$ in diameter, N.A: 0.22$)$ and coupled to the $10 \mu \mathrm{m}$ slit of a compact spectrometer located at the main unit of the instrument. The main unit of the instrument consisted of a specially adapted 
backpack, in which both the spectrometer and the personal computer were enclosed. The spectrometer was a crossed Czerny-Turner design (HR2000 Model, Ocean Optics Incorporated, FL, USA), with a holographic diffraction grating of 1200 grooves $\mathrm{mm}^{-1}$. This configuration provided a spectral resolution of $0.05 \mathrm{~nm} /$ pixel in the spectral range of $240-340 \mathrm{~nm}$. It was equipped with a built-in mono-dimensional Charge-Coupled Device (CCD) array (2048 pixels) for the optical detection. Conversely, the laser head and all the optical arrangements were housed in the hand-held probe. A fiber-optic cable guided the plasma emission from the probe to the spectrograph. All of the system was controlled wirelessly by means of a hand-held Personal Digital Assistant (PDA) device that permitted data visualization as well as control of the spectrometer and the laser parameters. Furthermore, a LabView routine was designed to carry out the calibration and quantification processes, among others.

\subsection{Samples}

A set of archaeological objects was analyzed in situ by LIBS in the Museum of Malaga. The Museum boasts prehistoric items from the most significant archaeological sites in the province, and samples were selected according to the criteria of representativity, morphology, and cultural significance. In this sense, the assembly of pieces represents a wide chronological and cultural range, from prehistory to the antiquity, and belongs to three different archaeological sites from the Early Bronze Age (AS1), Final Bronze Age (AS2), and Iron Age (AS3). Photographs of a selection of these metallic objects are shown in Figure 1. Although the pieces have different shapes and sizes, this is not a restriction for LIBS, since samples are positioned into the nozzle of the portable analyzer and the experimental conditions are maintained. Additional information regarding the samples is summarized in Table 1.

(A)

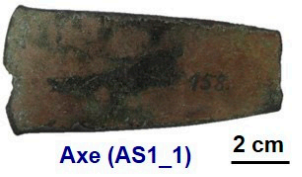

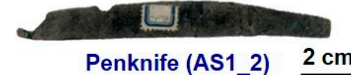

Penknife (AS1_2) $2 \mathrm{~cm}$

Chisel (AS1_7) $2 \mathrm{~cm}$
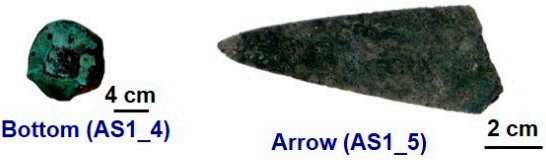

(B)
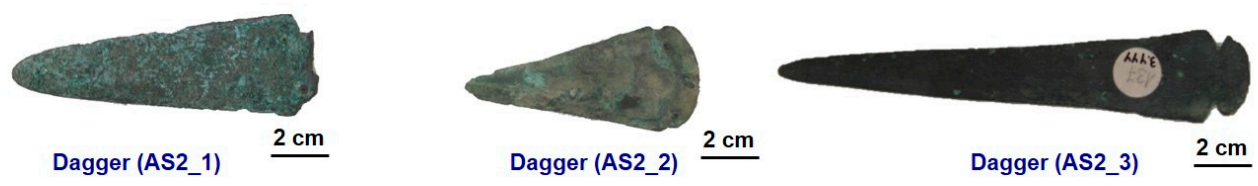

(C)
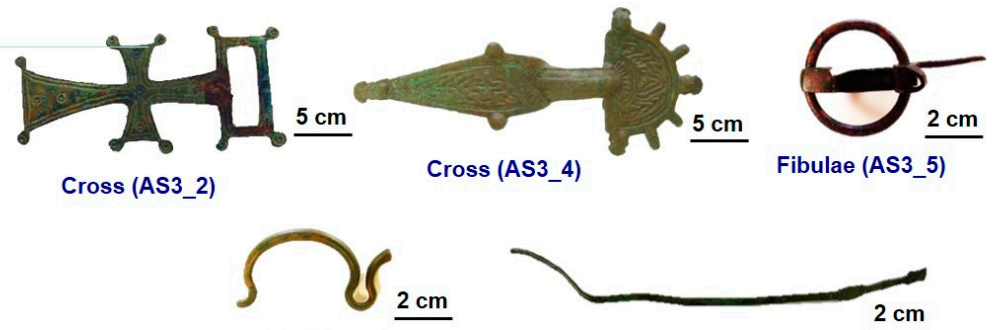

Buckle (AS3_12)
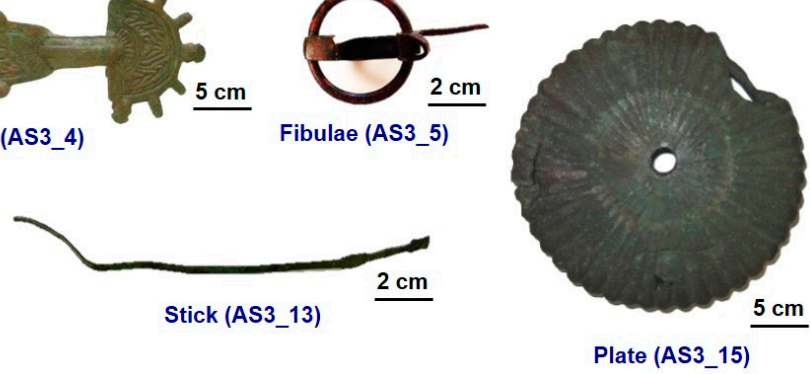

Figure 1. Photographs of selected archaeological objects characterized by laser-induced breakdown spectrometry (LIBS): (A) archaeological site 1, (B) archaeological site 2, and (C) archaeological site 3. 
Table 1. Archaeological information about the thirty ancient artifacts analyzed using LIBS.

\begin{tabular}{|c|c|c|c|}
\hline Item & Reference Code & Dating & Typology \\
\hline 1 & AS1_1 & Early Bronze Age & Axe \\
\hline 2 & AS1_2 & Early Bronze Age & Penknife \\
\hline 3 & AS1_3 & Early Bronze Age & Axe \\
\hline 4 & AS1_4 & Early Bronze Age & Bottom \\
\hline 5 & AS1_5 & Early Bronze Age & Chisel \\
\hline 6 & AS1_6 & Early Bronze Age & Chisel \\
\hline 7 & AS1_7 & Early Bronze Age & Arrow \\
\hline 8 & AS2_1 & Final Bronze Age & Axe \\
\hline 9 & AS2_2 & Final Bronze Age & Axe \\
\hline 10 & AS2_3 & Final Bronze Age & Axe \\
\hline 11 & AS3_1 & Iron Age & Buckle \\
\hline 12 & AS3_2 & Iron Age & Cross \\
\hline 13 & AS3_3 & Iron Age & Cross \\
\hline 14 & AS3_4 & Iron Age & Cross \\
\hline 15 & AS3_5 & Iron Age & Fibulae \\
\hline 16 & AS3_6 & Iron Age & Fibulae \\
\hline 17 & AS3_7 & Iron Age & Fibulae \\
\hline 18 & AS3_8 & Iron Age & Coin \\
\hline 19 & AS3_9 & Iron Age & Votive Cup \\
\hline 20 & AS3_10 & Iron Age & Bronze head \\
\hline 21 & AS3_11 & Iron Age & Nail \\
\hline 22 & AS3_12 & Iron Age & Buckle \\
\hline 23 & AS3_13 & Iron Age & Stick \\
\hline 24 & AS3_14 & Iron Age & Buckle \\
\hline 25 & AS3_15 & Iron Age & Plate \\
\hline 26 & AS3_16 & Iron Age & Earring \\
\hline 27 & AS3_17 & Iron Age & Spearhead \\
\hline 28 & AS3_18 & Iron Age & Scissors \\
\hline 29 & AS3_19 & Iron Age & Ring \\
\hline 30 & AS3_20 & Iron Age & Ring \\
\hline
\end{tabular}

A LIBS reference library containing silver (Ag), aluminum (Al), arsenic (As), carbon (C), calcium $(\mathrm{Ca})$, chromium $(\mathrm{Cr})$, copper $(\mathrm{Cu})$, iron $(\mathrm{Fe})$, magnesium $(\mathrm{Mg})$, manganese $(\mathrm{Mn})$, lead $(\mathrm{Pb})$, silicon ( $\mathrm{Si}$ ), tin ( $\mathrm{Sn})$, and titanium (Ti) was built from standard reference materials provided by Sigma Aldrich with $99.90 \%$ (p/p) of purity. To achieve an acceptable degree of accuracy in the results and to ensure the representativeness of the data, the following sampling procedure was carried out: The LIBS spectrum was acquired by averaging 50 laser shots on ten adjacent positions to obtain a typical spectrum of each sample by averaging all measurements.

\subsection{Method}

The LIBS methodological protocol used for archaeometallurgical analysis is described in Figure 2. As shown, the procedure outline in the flowchart is based on three basic steps to attain a chronocultural study of the metallic objects. In a first step, the visual inspection offers general information (provided by the Museum's conservator) about the manufacturing technology of the object, as well as a global vision concerning the environmental degradation of the object during its history. However, the visual inspection presents limitations and, although it can give hints about the origin, the raw material employed, or even its heat treatment, etc., it does not give certainty and needs to be accompanied by a chemical characterization. In this sense, the spectral analysis can be organized in two approaches: a surface (lateral and in-depth) analysis in order to examine the environmental elements present in the sample, and a chemical assessment of the metal alloy. The final step consists of the chronocultural sorting [24] of the ancient objects, taking these considerations into account. The identification and 
recognition of certain elements are important factors in archaeometallurgy because they could be used as chronological indicators.

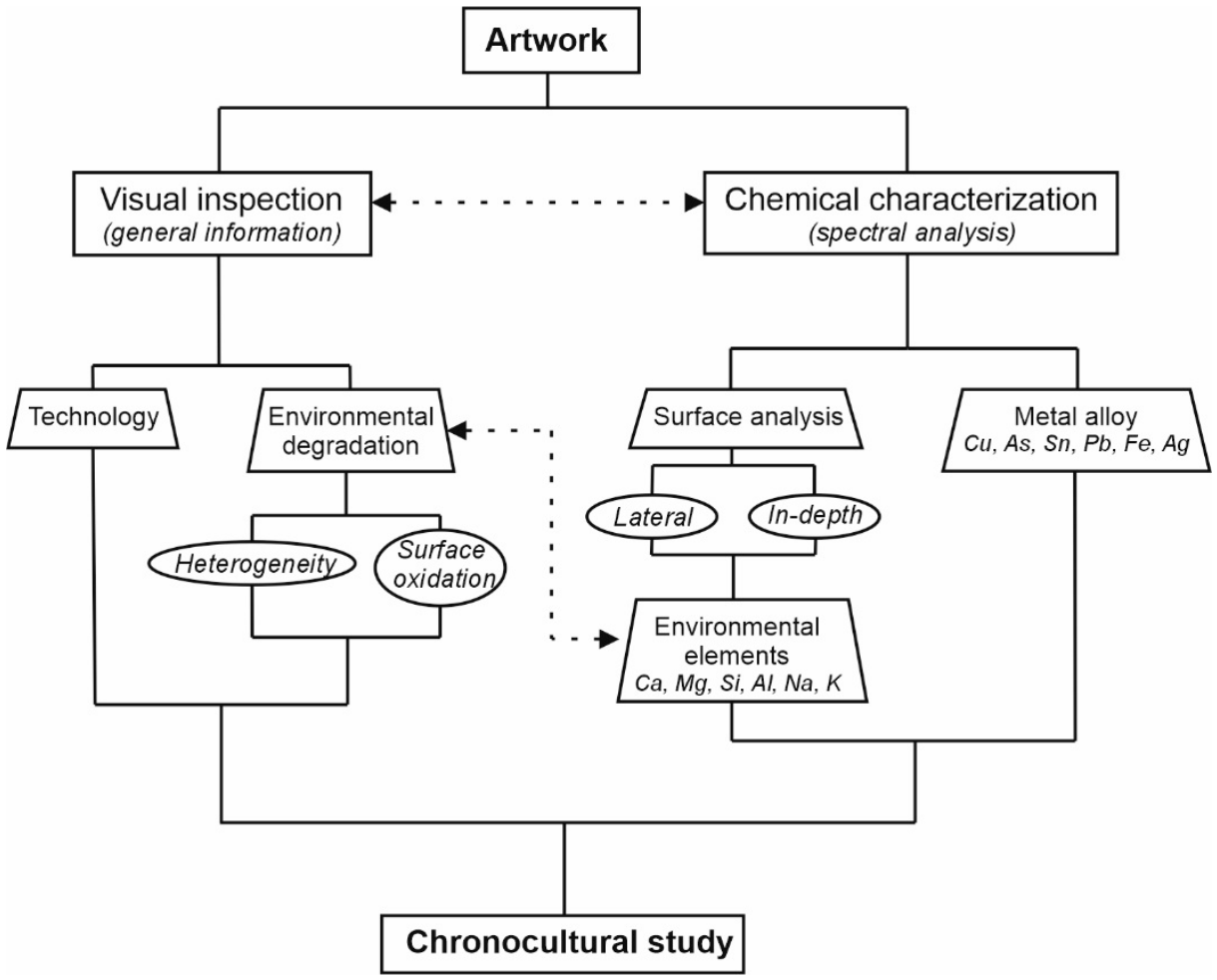

Figure 2. LIBS methodological protocol used for the chronocultural sorting of metallic objects.

\section{Results and Discussion}

\subsection{In-Situ Chemical Characterization in the Museum of Malaga}

The spectra recorded by the portable LIBS instrument covered the spectral range of 240-340 nm. This spectral window was chosen since all elements of interest could be measured simultaneously, ensuring the minimum damage to the sample by laser ablation. In this sense, the technique is minimally destructive; the dimensions of the crater were $100 \mu \mathrm{m}$ in diameter and approximately $100 \mu \mathrm{m}$ deep for the 50 laser shots achieved in each sampling position, making it virtually imperceptible to the naked eye. The recognition of the sample's constituents provides a source of information about the raw material employed in its production and the origin of the objects.

Figure 3 shows the LIBS spectra corresponding to different archaeometallurgical objects. The most important emission lines of the elements of interest in this spectral window are summarized in Table 2. LIBS spectra were acquired by averaging 50 laser shots on five adjacent positions for each sample to obtain a typical spectrum of the material. As observed, the differences among materials are appreciable. $\mathrm{Ca}, \mathrm{Mg}$, and $\mathrm{Si}$ are environmental elements, and their presence in the LIBS spectra is closely related to the environmental degradation of the pieces. Figure $3 \mathrm{~A}$ shows that the Axe from the Early Bronze Age (AS1_3) was mainly composed of $\mathrm{Cu}$ and As, the typical composition of ancient bronzes [31]. On the other hand, the Cross (AS3_2) presents intense emission from $\mathrm{Cu}, \mathrm{Sn}$, and $\mathrm{Pb}$, which reveals the composition of the Iron Age (Figure 3B). In addition, traces of Fe were observed. Figure 3C,D belong to samples from the Iron Age. Figure 3C illustrates that the Spearhead (AS3_17) is mainly composed of Fe, while the Ring (AS3_19) exhibits the emission lines of Cu and Ag in the spectral range of 240-340 nm (Figure 3D). 
(A)

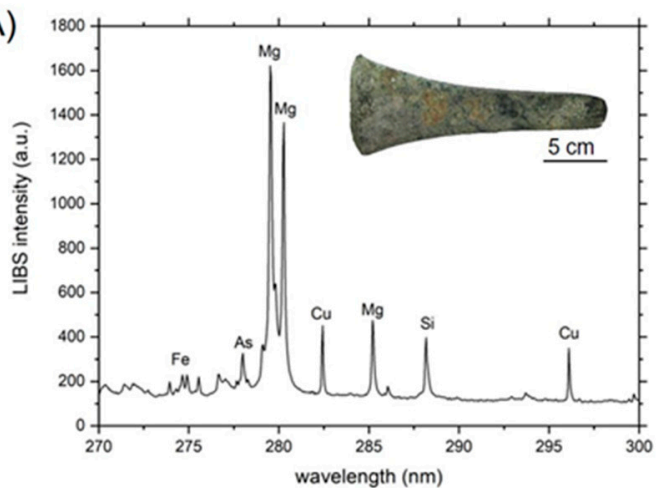

(C)

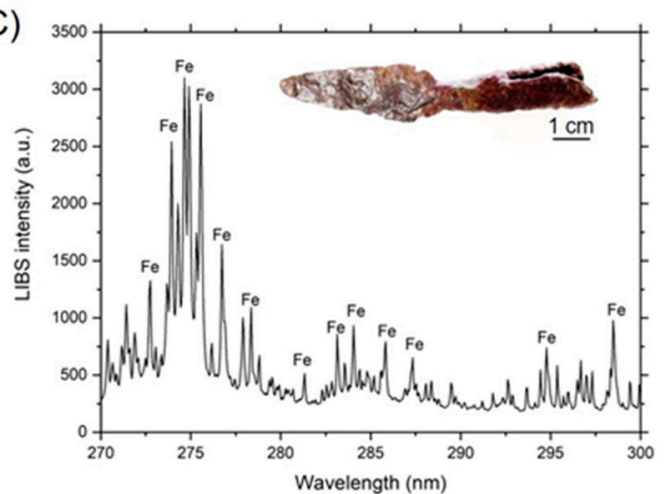

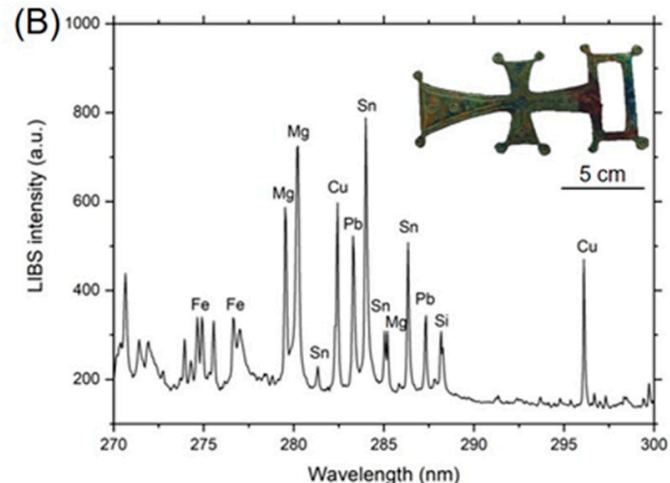

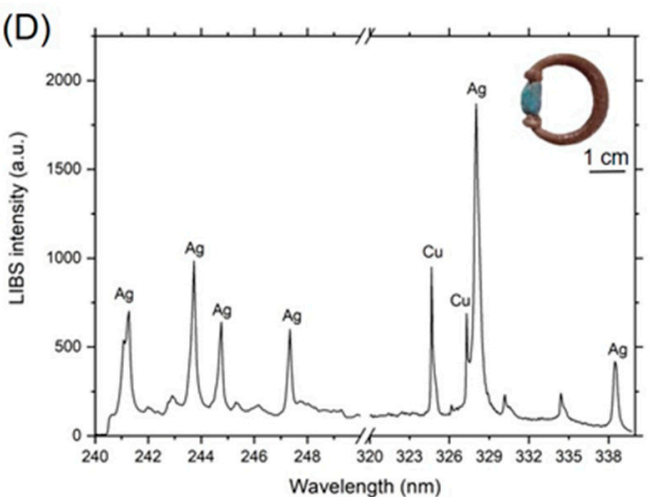

Figure 3. Spectra of the (A) Axe (AS1_3; copper-based alloy; Early Bronze Age), (B) Cross (AS3_2; copper-based alloy; Iron Age), (C) Spearhead (AS3_17; iron-based alloy; Iron Age), and (D) Ring (AS3_19; silver-based alloy; Iron Age).

Table 2. Analytical emission lines used for identifying elements in the archaeometallurgical objects of Malaga's museum.

\begin{tabular}{|c|c|}
\hline Element & Wavelength ${ }^{\mathrm{a}, \mathrm{b}}$ (nm) \\
\hline Ag & $\begin{array}{c}240.24 \text { (II) (31000), } 241.13 \text { (II) (180000), } 242.95 \text { (II) (190000), } 243.78 \text { (II) (450000), } 247.37 \text { (II) (140000), } \\
328.07 \text { (I) (55000r), } 338.29 \text { nm (I) (28000r) }\end{array}$ \\
\hline $\mathrm{Al}$ & 257.58 (I) (480), 281.70 (II) (650), 308.30 (I) (4500), 309.36 (I) (7200) \\
\hline As & 278.02 (I) (170r) \\
\hline $\mathrm{Ca}$ & 299.73 (I) (8), 300.68 (I) (10), 315.88 (I) (170), 317.93 (I) (180) \\
\hline $\mathrm{Cu}$ & 261.84 (I) (2500r), 282.44 (I) (1250r), 296.11 (I) (2500r), 324.75 (I) (10000r), 327.40 (I) (10000r) \\
\hline $\mathrm{Fe}$ & 259.94 (II) (23000), 274.04 (II) (250), 274.35 (I) (2750), 274.71 (II) (29000), 275.09 (I) (830), 275.57 (II) (110000) \\
\hline $\mathrm{Mg}$ & 280.27 (II) (12), 285.21 (I) (50) \\
\hline $\mathrm{Si}$ & 288.16 (I) (1000) \\
\hline Sn & 281.35 (I) (3800), 283.99 (I) (13000r), 285.06 (I) (7500), 286.33 (I) (10000), 326.23 (I) (15000r) \\
\hline $\mathrm{Pb}$ & 280.20 (I) (25000r), 282.32 (I) (14000r), 283.30 (I) (35000), 287.33 (I) (14000) \\
\hline
\end{tabular}

${ }^{a}$ Wavelengths are followed by (I) or (II) depending on whether they refer to emission from neutral atoms or emission from singly charged ions, respectively. ${ }^{\mathrm{b}}$ Relative intensity of the emission lines ( $\mathrm{r}$ indicates that it is a resonant line).

In a first step, visual inspection offers general information about the technology employed during the manufacturing process, and the heterogeneities and surface oxidation (heat treatment and/or environmental degradation) can be related to the state of conservation of the artwork. However, if we only attend to this information, errors in the dating of the piece may occur. In some cases, especially in bronze-based alloys, the piece could be manufactured from the foundry of other bronze objects, which indicates an archaeological recycling. As an example, Figure 4 shows the different metallic alloys used in the manufacture of the most important piece in the collection, a Roman Head (AS3_10). Each spectrum refers to a specific area of the bronze Roman Head. The selected spectral lines are summarized in Table 2. As shown, the metallic alloy depends on the inspected area. The noblest area is the decorative detail of the head, which contains Ag. In contrast, the rest of the piece presents 
copper-based alloys of different chemical compositions: $\mathrm{Cu}-\mathrm{Pb}, \mathrm{Cu}-\mathrm{Sn}$, and $\mathrm{Cu}-\mathrm{Sn}-\mathrm{Pb}$. This fact could indicate that, as commented above, its origin may be related to a recasting of different bronze objects. Thus, chemical information extracted from ancient objects as well as the technology employed in its production becomes fundamental for a better understanding of historic events.
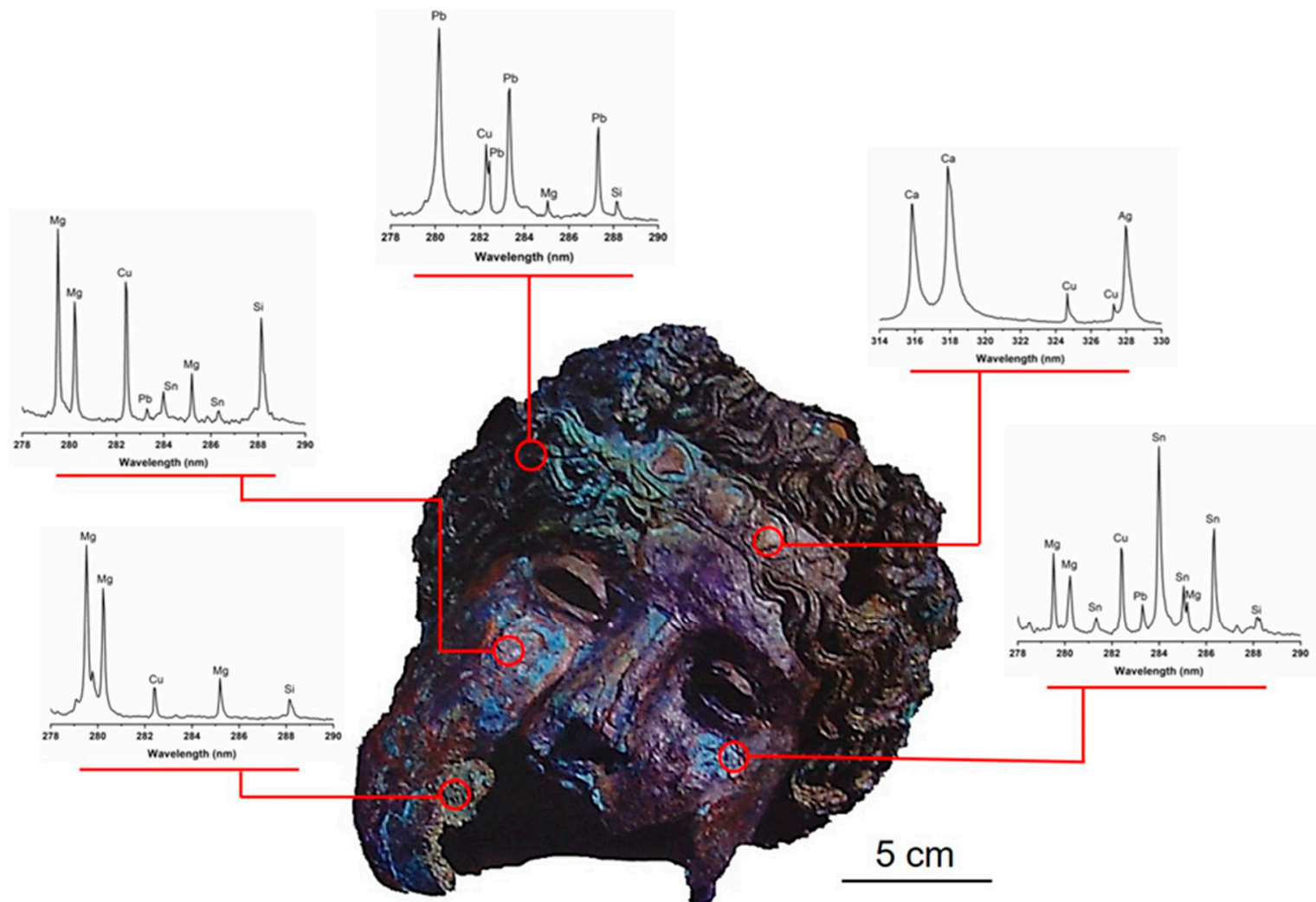

Figure 4. Detail of the Roman Head (AS3_10) illustrating each of the studied sampling areas and their corresponding LIBS spectra.

Belonging to the same era, archaeologists found remnants of chimneys in which bronze objects were manufactured. The results are presented in Figure 5. The spectrum shown in Figure 5 corresponds to the laser shot \#5 of the depth profiling analysis and reveals the presence of $\mathrm{Cu}, \mathrm{Sn}$, and $\mathrm{Pb}$. Si, Mg, and Fe were also detected, but their content was directly related to the chemical composition of the nozzle-clay. In order to estimate the thickness of the bronze layer in the nozzle's surface and to demonstrate that the presence of $\mathrm{Cu}, \mathrm{Sn}$, and $\mathrm{Pb}$ is owed to the manufacturing process, a depth profile analysis was performed. The normalized LIBS intensities of $\mathrm{Si}$ (I) at $288.16 \mathrm{~nm}$ and $\mathrm{Cu}$ (I) at $324.75 \mathrm{~nm}$ are plotted in the graph. An averaged ablation rate value of $1.5 \mu \mathrm{m}$ per pulse was estimated on the material studied. As seen, about 200 consecutive laser shots were necessary to remove the bronze thickness, approximately $350 \mu \mathrm{m}$. These results could indicate its use in the bronze's foundry. 

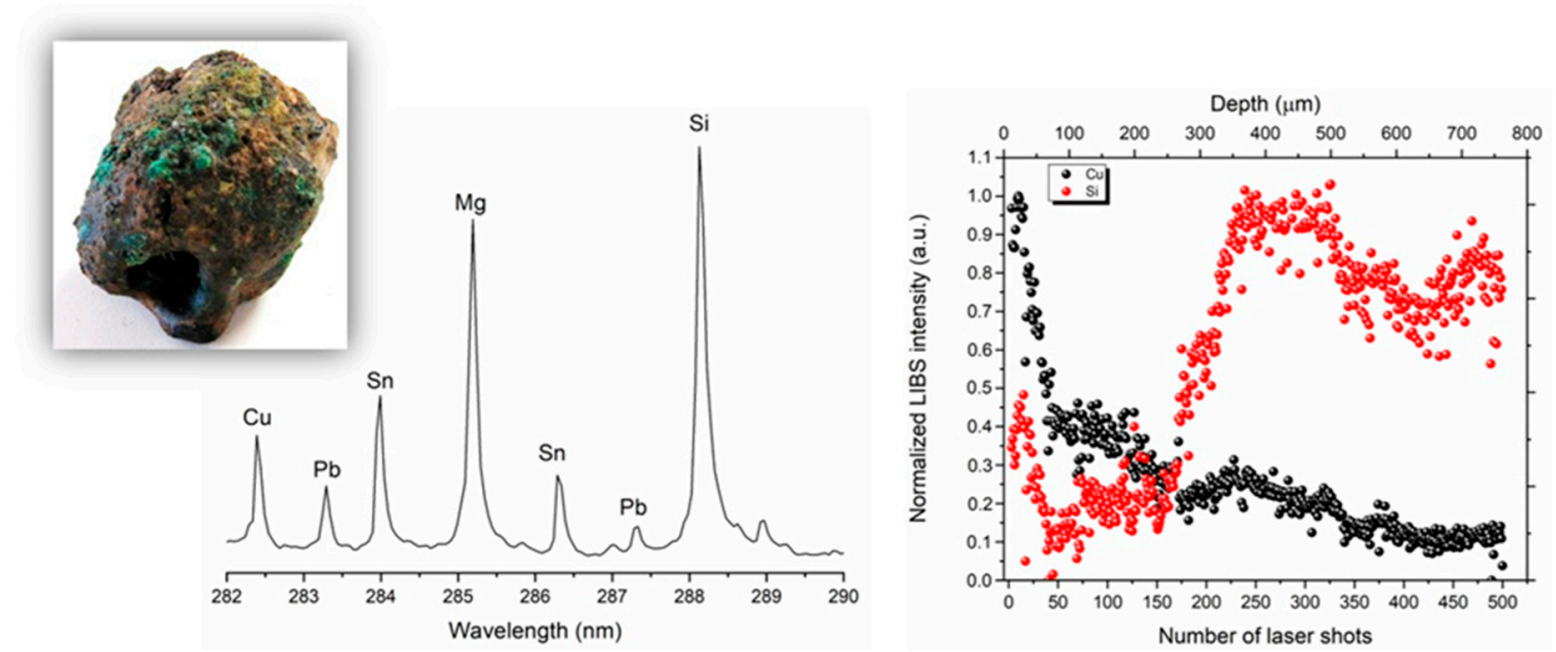

Figure 5. Profile analysis as a function of the number of laser pulses in a nozzle's chimney used in the foundry of bronze: (red) Si (I) at $288.16 \mathrm{~nm}$ and (black) Cu (I) at $324.75 \mathrm{~nm}$. The LIBS spectra correspond to laser shot \#5.

\subsection{Libraries for Spectrum Identification: Method of Normalized Coordinates}

Given the great compositional diversity, textural differences, and surface alterations of artworks, the use of advanced statistical algorithms is essential for the recognition and classification of archaeological findings. In this work, the method of normalized coordinates, based on the algebraic determination of the "problem spectrum" coordinates with respect to the LIBS spectral library, is proposed [36]. These coordinates are the identification weights of each component ( $\mathrm{Ag}, \mathrm{As}, \mathrm{Al}, \mathrm{C}$, $\mathrm{Ca}, \mathrm{Cr}, \mathrm{Cu}, \mathrm{Fe}, \mathrm{Mg}, \mathrm{Mn}, \mathrm{Pb}, \mathrm{Si}, \mathrm{Sn}$, and Ti standard reference materials) of the library. The problem of calculating the position of a specific spectrum with respect to a library is algebraically expressed as the problem of finding the coordinate's $a_{i}$ of the sample vector $p$ in a specific base $\{v\}$ (Equation (1)).

$$
p_{j}=\sum_{i=1}^{N} a_{i} \cdot v_{j i},
$$

where $N$ is the number of spectra in the reference LIBS library, $p_{j}$ is the problem spectrum at the wavelength $j, v_{j i}$ is the value of the wavelength $j$ of the spectrum $i$ in the library, and $a_{i}$ is the contribution of each spectrum of the library in the problem spectrum. Then, there is a system with the same number of equations and wavelengths $(\mathrm{M})$, where it is necessary to solve only $\mathrm{N}$ unknown quantities. As a matrix, Equation (1) can be expressed as:

$$
p=V \cdot a,
$$

where $p$ is the column problem vector $(\mathrm{M} \times 1), a$ is the column coordinate vector in the new base $(\mathrm{N} \times 1)$, and $V$ is the matrix that represents the new base (the library), with its vectors located in each column $(\mathrm{M} \times \mathrm{N})$. Once the matrix is resolved, it is possible to obtain a representative value of the relative contribution of each component by normalizing each coordinate $a_{i}$ to the sum of all coordinates [36]. Thus, an $a_{i}$ value of 1 means that the spectrum $i$ of the library perfectly matches with that of the unknown sample. In contrast, if $a_{i}$ is 0 , it indicates that the spectrum $i$ of the library is totally different from that of the problem spectrum. Furthermore, an intermediate value of $a_{i}$ means that the problem spectrum is composed of a mixture of several spectra from the LIBS reference library.

Once the in-situ chemical characterization in the Museum of Malaga was performed, LIBS spectra were simultaneously compared with the LIBS reference library (see Section 2.2.: Samples) to obtain the normalized coordinates. The results are presented in Figure 6. Figure 6A plots the normalized coordinates ( $y$ axis) of the inspected archaeological samples ( $x$ axis). In this work, only copper-based 
alloys (Table 1, items \#1-25) were considered for the calculation of the normalized coordinates, while iron- and silver-based alloys were excluded from this study. As seen, the compositional profile reveals the presence of $\mathrm{As}, \mathrm{Cu}, \mathrm{Fe}, \mathrm{Pb}$, and $\mathrm{Sn}$ in each sample. The weights for the normalized copper coordinate are located between 0.85 and 0.95 for samples belonging to AS1, around 0.5 for samples belonging to AS2, and in the range 0.6-0.95 for samples belonging to AS3. In the case of As, a key element for the chronocultural sorting of archaeological samples, its content is associated to AS1 and AS2. Concerning AS3, the LIBS spectrum of the samples associated with this archaeological site presents a significant statistical weight in the normalized coordinates of iron, lead, and tin. It must be taken into account that the presence of $\mathrm{Ca}, \mathrm{Mg}$, and $\mathrm{Si}$ in the LIBS spectra of the inspected objects is closely related to the environmental degradation of the objects during their history. In this sense, the contributions of these elements were also included in the LIBS reference library.
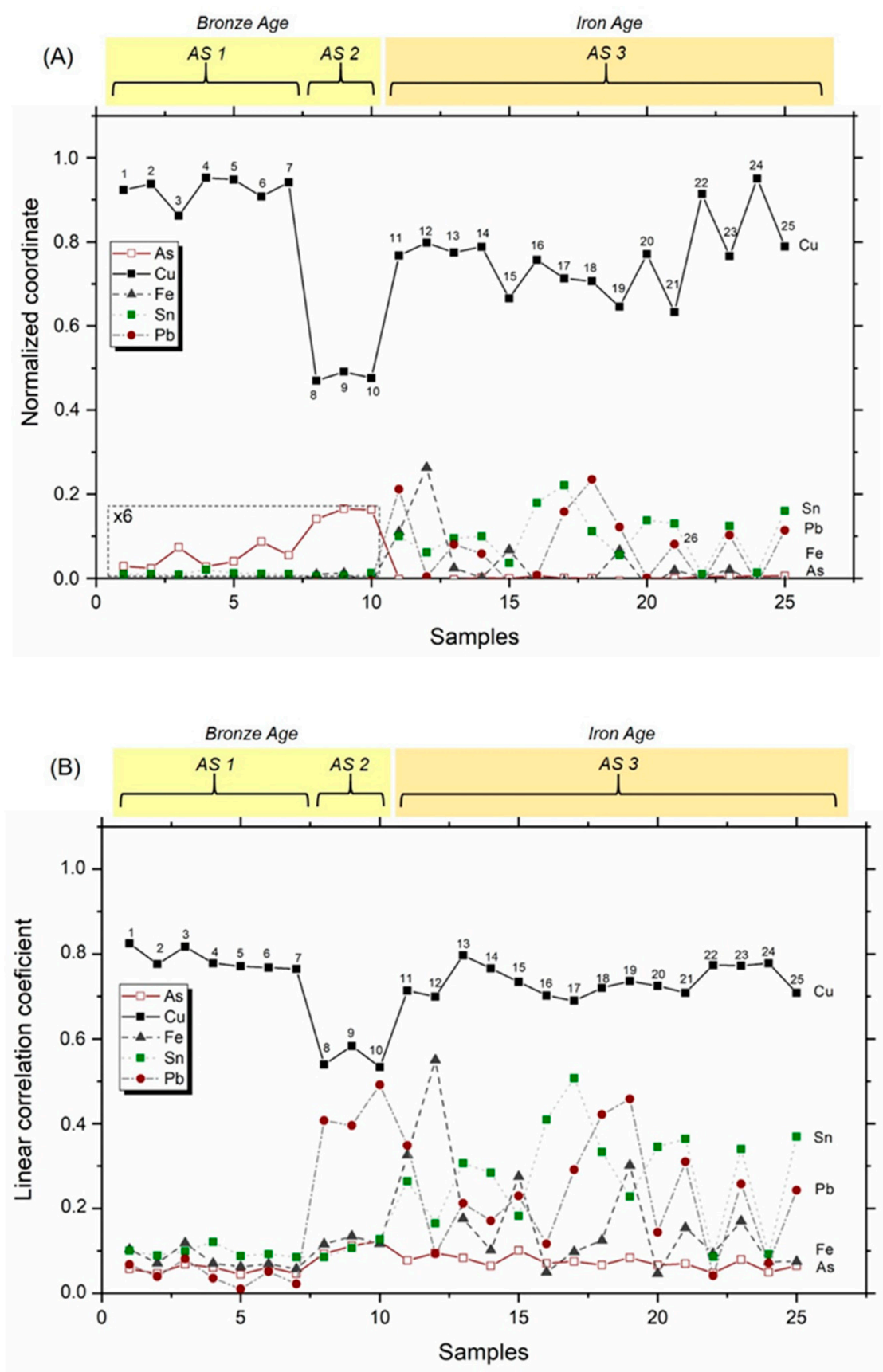

Figure 6. (A) Normalized coordinates and (B) linear correlation coefficients of $\mathrm{As}, \mathrm{Cu}, \mathrm{Fe}$, Sn, and $\mathrm{Pb}$ for the analyzed copper-based alloys. 
Since the type of metal alloy used has evolved with time, a knowledge of the elemental composition of this kind of sample makes possible the assignment of the manufacturing period and the chronocultural sorting of the metallic objects. In this sense, the employment of the method of normalized coordinates offers a semi-quantitative analysis of the inspected objects, which could help to sort between different archaeological sites, which, in this case, means to sort in time.

To corroborate the applicability of the method of normalized coordinates to the field of cultural heritage, a comparison with respect to the linear correlation method has been performed. Figure $6 \mathrm{~B}$ plotted the linear correlation coefficient (y axis) of the inspected archaeological samples ( $x$ axis). If we observe in detail, a number of anomalies in the results are noticed. Thus, samples from AS2 present the highest coefficient value for lead, around 0.4-0.5. In this case, the linear correlation method fails due to the fact of the interference of the emission line of $\mathrm{Mg}$ (II) at $280.27 \mathrm{~nm}$ with $\mathrm{Pb}$ (I) at $280.20 \mathrm{~nm}$. In addition, the identification of samples from AS3 also fails, since the method identifies elements not present in the LIBS spectrum. In this sense, beyond the discrimination capacity, the main advantage of the method of normalized coordinates over linear correlation is that the identification is based on the simultaneous comparison of all the spectra in the LIBS reference library, allowing the analysis of heterogeneous materials-and not in a successive comparison, as occurs in the linear correlation method.

In addition, it could be interesting to estimate the similarities or differences between the twenty-five inspected copper-based alloy samples. Thus, the Euclidean distance from the original LIBS spectra was calculated as expressed in Equation (3):

$$
d_{k l}=\left[\sum_{j=1}^{m}\left(p_{k j}-p_{l j}\right)^{2}\right]^{1 / 2} .
$$

In this equation, $m$ is the number of samples, $p_{k j}$ is the problem spectrum of the sample $k$, and $p_{l j}$ is the problem spectrum of the sample $l$. The Euclidean distance values calculated for each archaeological sample are plotted in a symmetric matrix (Figure 7). The higher the value of the Euclidean distance, the easier the differentiation between samples. Taking a look along the diagonal, the degree of similarity between samples belonging to the same archaeological site is, as expected, quite large, especially in AS1 and AS2. In contrast, in AS3, the Euclidean distance values are a little bit higher. As seen, the color scale indicates that samples belonging to AS2 can be clearly differentiated from AS1 and AS3. On the other hand, an intermediate degree of similarity exists between AS1 and AS3, presenting Euclidean distance values around 10-15, except for sample AS3_8, which is quite different from the rest of the samples belonging to the same archaeological site. In the Euclidean distance analysis, contrarily to the normalized coordinate method, LIBS spectra are directly compared with each other in the 278-290 nm spectral range. In particular, AS3_8 presents a greater content of environmental elements, and the differences found are probably due to this fact. Nonetheless, the results obtained are complementary to those obtained by the method of the normalized coordinates, and they reveal that differentiating between archaeological sites seems feasible. 


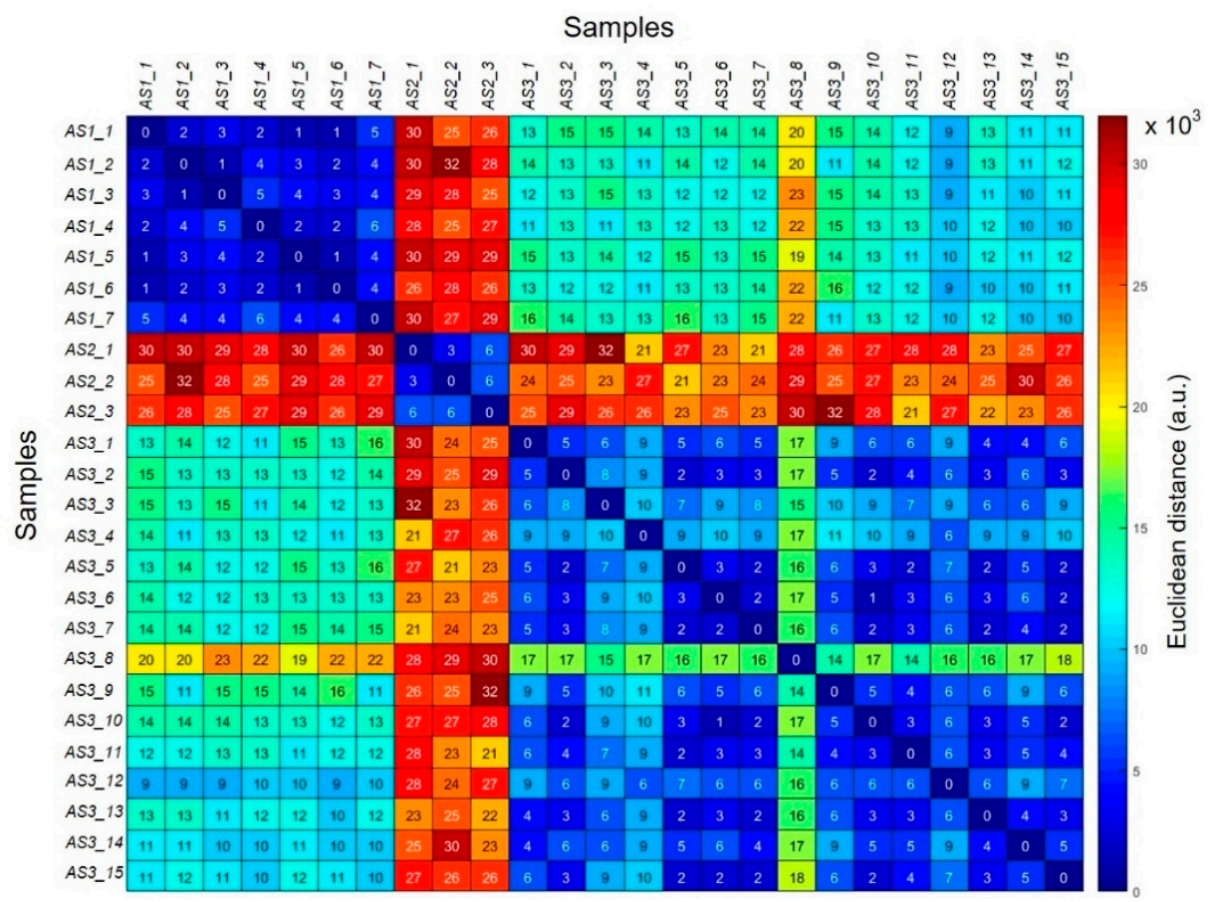

Figure 7. Distance values calculated for each archaeological sample.

Once the weights of each normalized coordinates were calculated, in order to corroborate the results obtained above, binary diagrams were constructed from the coordinates of copper, lead, and tin. As revealed in Figure 8, it is possible to distinguish several clusters of data. The binary diagram of $\mathrm{Cu}$-Sn (Figure 8A) clearly resolves the three samples' assemblies, presenting a normalized copper coordinate higher than 0.4: values of $0.45-0.55,0.6-0.8$ and $0.85-0.95$ for AS2, AS3, and AS1, respectively. In contrast, although the $\mathrm{Cu}-\mathrm{Pb}$ binary diagram also differentiates between the three archaeological sites, the resolution between groups is not as remarkable as in the previous case (Figure 8B). No differences were noted in the $\mathrm{Pb}-\mathrm{Sn}$ binary diagram (Figure $8 \mathrm{C}$ ). Moreover, no correlation was found between samples of the same category, e.g., fibulae and rings, which could indicate that similar samples have different origins or manufacturers.

(A)

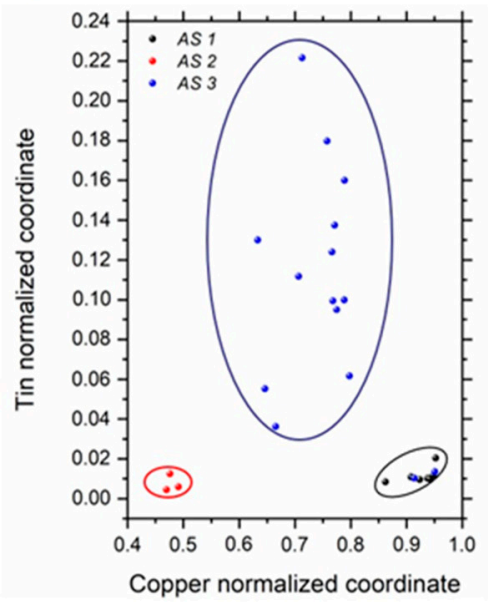

(B)

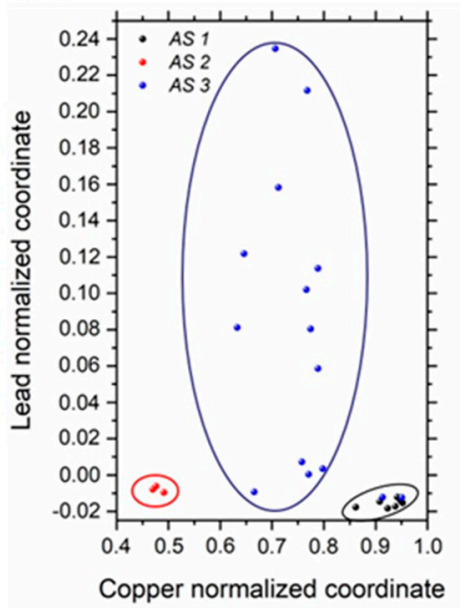

(C)

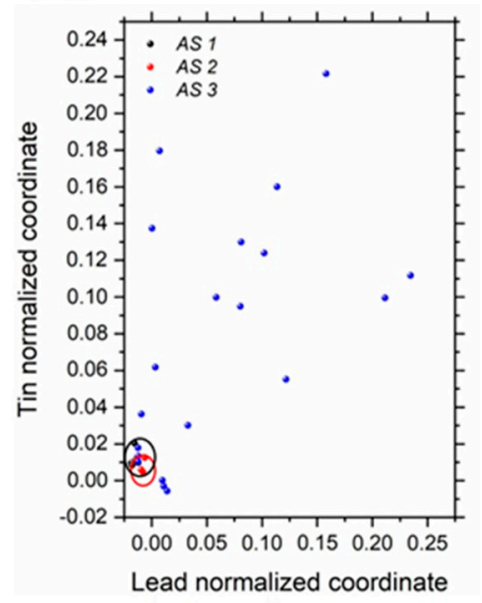

Figure 8. Diagram of normalized (A) copper-tin, (B) copper-lead, and (C) lead-tin coordinates obtained by LIBS for the samples belonging to AS $1(\bullet)$, AS $2(\bullet)$, and AS $3(\bullet)$. 


\section{Conclusions}

In this work, it has been demonstrated that the LIBS technique is a powerful tool for the chemical characterization and sorting of archaeological metallic objects, regardless of the great compositional diversity, textural differences, and surface alterations of artworks. Compositional heterogeneities must be taken into account in order to obtain reliable information about their chemical composition.

The coordinate-obtaining method has been presented here as an advanced statistical algorithm for the recognition and classification of archaeological findings. This method provides the statistical weights of each element in the sample. Once the in-situ chemical characterization was performed in the Museum of Malaga, LIBS spectra were simultaneously compared with a LIBS reference library to obtain the normalized coordinates. Only copper-based alloys were considered for this study. To corroborate the applicability of the method of normalized coordinates to the field of cultural heritage, a comparison with respect to the linear correlation method was performed. The results suggest that the advantage of the proposed algorithm over linear correlation is that the identification is based on the simultaneous comparison of all the spectra in the LIBS reference library, allowing the analysis of heterogeneous materials_-not in a successive comparison, as occurs in the linear correlation method.

Similarities and differences between groups were evaluated in terms of Euclidean distance. The results reveal that differentiation between archaeological sites was feasible, and that samples belonging to AS2 could be clearly differentiated from those belonging to AS1 and AS3. However, an intermediate degree of similarity exists between AS1 and AS3. The data were corroborated using the binary diagrams of $\mathrm{Cu}-\mathrm{Sn}$ and $\mathrm{Cu}-\mathrm{Pb}$.

Author Contributions: Conceptualization, F.J.F., L.M.C. and J.J.L.; methodology, F.J.F. and L.M.C.; investigation F.J.F., L.M.C. and J.J.L.; data curation F.J.F.; writing—original draft preparation, F.J.F. and L.M.C.; writing-review and editing, F.J.F., L.M.C. and J.J.L.; supervision, J.J.L.; funding acquisition, J.J.L. All authors have read and agreed to the published version of the manuscript.

Funding: This research was funded by the SPANISH MINISTERIO DE ECONOMIA Y COMPETITIVIDAD, grant number CTQ2017-82137P.

Acknowledgments: The authors would like to acknowledge the Archaeological Museum of Malaga for making possible the in-situ measurements, and in particular to M. Cortés (Doctor in History) and S. Fernández (conservator in the Museum of Malaga) for their kind assistance and collaboration during the analysis, as well as for providing the information concerning the analyzed samples.

Conflicts of Interest: The authors declare no conflict of interest.

\section{References}

1. Adriaens, A. Non-destructive analysis and testing of museum objects: An overview of 5 years of research. Spectrochim. Acta Part B 2005, 60, 1503-1516. [CrossRef]

2. Ciliberto, E.; Spoto, G. (Eds.) Modern Analytical Methods in Art and Archaeology; Wiley Interscience: New York, NY, USA, 2000.

3. Adams, A.; Adriaens, A.; Aerts, A.; De Raedt, I.; Janssens, K.; Schalm, O. Micro and surface analysis in art and archaeology. J. Anal. At. Spectrom. 1997, 12, 257-265. [CrossRef]

4. De Benedetto, G.E.; Laviano, R.; Sabbatini, L.; Zambonin, P. Infrared spectroscopy in the mineralogical characterization of ancient pottery. J. Cult. Herit. 2002, 3, 177-186. [CrossRef]

5. Caneve, L.; Guarneri, M.; Lai, A.; Spizzichino, V.; Ceccarelli, S.; Mazzei, B. Nondestructive laser based techniques for biodegradation analysis in cultural heritage. Ndt E Int. 2019, 108-113. [CrossRef]

6. Paparazzo, E. Scanning auger microscopy studies of an ancient bronze. J. Vac. Sci. Technol. 2001, 19, 1126. [CrossRef]

7. Mantler, M.; Schreiner, M. X-ray fluorescence spectrometry in art and archaeology. X-ray Spectrom. 2000, 29, 3-17. [CrossRef]

8. Medina-Alcaide, M.A.; Cabalin, L.M.; Laserna, J.J.; Sanchidrián, J.L.; Torres, A.J.; Intxaurbe, I.; Cosano, S.; Romero, A. Multianalytical and multiproxy approach to the characterization of a Paleolithic lamp. An example from Nerja cave (Malaga, Spain). J. Archaeol. Sci. Rep. 2019, 28, 102021. [CrossRef] 
9. Bourgarit, D.; Mille, B. The elemental analysis of ancient copper-based artifacts by inductively-coupled-plasma atomic-emission spectrometry: An optimized methodology reveals some secrets of the Vix crater. Meas. Sci. Technol. 2003, 14, 1538. [CrossRef]

10. Ghisalberti, E.L.; Godfrey, I.M. Application of nuclear magnetic resonance spectroscopy to the analysis of organic archaeological materials. Stud. Conserv. 1998, 43, 215-230.

11. Stamatakis, G.; Knuutinen, U.; Laitinen, K.; Spyros, A. Analysis and aging of unsaturated polyester resins in contemporary art installations by NMR spectroscopy. Anal. Bioanal. Chem. 2010, 398, 3203-3214. [CrossRef]

12. Bernardini, F.; Leghissa, E.; Prokop, D.; Velušček, A.; De Min, A.; Dreossi, D.; Donato, S.; Tuniz, C.; Princivalle, F.; Montagnari Kokelj, M. X-ray computed microtomography of Late Copper Age decorated bowls with cross-shaped foots from central Slovenia and the Trieste Karst (North-Eastern Italy): Technology and paste characterization. Archaeol. Anthropol. Sci. 2019, 11, 4711-4728. [CrossRef]

13. Bernardini, F.; Vinci, G.; Prokop, D.; Barro Savonuzzi, L.; De Min, A.; Lenaz, D.; Pincivalle, F.; Cocca, E.; Kasztovszky, Z.; Harsányi, I.; et al. A multi-analytical study of Bronze Age pottery from the UNESCO site of Al-Khutm (Bat, Oman). Archaeol. Anthropol. Sci. 2020, 12, 163. [CrossRef]

14. Prochazka, D.; Zikmund, T.; Pořízka, P.; Břínek, A.; Klus, J.; Šalplachta, J.; Kynický, J.; Novotný, J.; Kaiser, J. Joint utilization of double-pulse laser-induced breakdown spectroscopy and X-ray computed tomography for volumetric information of geological samples. J. Anal. At. Spectrom. 2018, 33, 1993-1999. [CrossRef]

15. Botto, A.; Campanella, B.; Legnaioli, S.; Lezzerini, M.; Lorenzetti, G.; Pagnotta, S.; Poggialini, F.; Palleschi, V. Applications of laser-induced breakdown spectroscopy in cultural heritage and archaeology: A critical review. J. Anal. At. Spectrom. 2019, 34, 81-103. [CrossRef]

16. Anglos, D.; Detalle, V. Laser-Induced Breakdown Spectroscopy. In Cultural Heritage Applications of LIBS; Springer: Berlin/Heidelberg, Germany, 2014; pp. 531-554.

17. Fortes, F.J.; Moros, J.; Lucena, P.; Cabalín, L.M.; Laserna, J.J. Laser-induced breakdown spectroscopy. Anal. Chem. Rev. 2013, 85, 640-669. [CrossRef]

18. Melessanaki, K.; Mateo, M.P.; Ferrence, S.C.; Betancourt, P.P.; Anglos, D. The application of LIBS for the analysis of archaeological ceramic and metal artifacts. Appl. Surf. Sci. 2002, 197-198, 156-163. [CrossRef]

19. Anglos, D. Laser-induced breakdown spectroscopy in heritage science. Phys. Sci. Rev. 2019, 4. [CrossRef]

20. Giakoumaki, A.; Melessanaki, K.; Anglos, D. Laser-induced breakdown spectroscopy (LIBS) in archaeological science-application and prospects. Anal. Bioanal. Chem. 2006, 387, 749. [CrossRef]

21. Fortes, F.J.; Laserna, J.J. The development of fieldable laser-induced breakdown spectrometer: No limits on the horizon. Spectrochim. Acta Part B 2010, 65, 975-990. [CrossRef]

22. Fortes, F.J.; Cuñat, J.; Cabalín, L.M.; Laserna, J.J. In-situ analytical assessment of historical buildings using a man portable laser system. Appl. Spectrosc. 2007, 61, 558-564. [CrossRef]

23. Cuñat, J.; Palanco, S.; Carrasco, F.; Simón, M.D.; Laserna, J.J. Portable instrument and analytical method using laser-induced breakdown spectrometry for in situ characterization of speleothems in karstic caves. J. Anal. At. Spectrom. 2005, 20, 295-300. [CrossRef]

24. López-Claros, M.; Fortes, F.J.; Laserna, J.J. Subsea spectral identification of shipwreck objects using laser-induced breakdown spectroscopy and linear discriminant analysis. J. Cult. Herit. 2018, 29, 75-81. [CrossRef]

25. Guirado, S.; Fortes, F.J.; Laserna, J.J. Multi-pulse excitation for underwater analysis of copper-based alloys using a novel remote laser-induced breakdown spectroscopy system. Appl. Spectrosc. 2016, 70, 618-626. [CrossRef] [PubMed]

26. Fortes, F.J.; Guirado, S.; Metzinger, A.; Laserna, J.J. A study of underwater stand-off laser-induced breakdown spectroscopy for chemical analysis of objects in the deep ocean. J. Anal. At. Spectrom. 2015, 30, 1050-1056. [CrossRef]

27. Guirado, S.; Fortes, F.J.; Laserna, J.J. Elemental analysis of materials in an underwater archaeological shipwreck using a novel remote laser-induced breakdown spectroscopy system. Talanta 2015, 137, 182-188. [CrossRef] [PubMed]

28. Lazic, V.; Colao, F.; Fantoni, R.; Spizzicchino, V. Recognition of archeological materials underwater by laser induced breakdown spectroscopy. Spectrochim. Acta Part B 2005, 60, 1014-1024. [CrossRef]

29. Corsi, M.; Cristoforetti, G.; Giuffrida, M.; Hidalgo, M.; Legnaioli, S.; Masotti, L.; Palleschi, V.; Salvetti, A.; Tognoni, E.; Vallebona, C.; et al. Archaeometric analysis of ancient copper artefacts by laser-induced breakdown spectroscopy technique. Microchim. Acta 2005, 152, 105. [CrossRef] 
30. Colao, F.; Fantoni, R.; Lazic, V.; Spizzichino, V. Laser-induced breakdown spectroscopy for semi-quantitative and quantitative analysis of artworks-application on multi-layered ceramics and copper based alloys. Spectrochim. Acta Part B 2002, 57, 1219. [CrossRef]

31. Fortes, F.J.; Cortes, M.; Simon, M.D.; Cabalin, L.M.; Laserna, J.J. Chronocultural sorting of archaeological bronze objects using Laser-Induced Breakdown Spectrometry. Anal. Chim. Acta 2006, 554, 136-143. [CrossRef]

32. Duchêne, S.; Detalle, V.; Bruder, R.; Sirven, J. Chemometrics and Laser induced breakdown spectroscopy (LIBS) analyses for identication of wall paintings pigments. Curr. Anal. Chem. 2010, 6, 60-65. [CrossRef]

33. Oztoprak, B.G.; Sinmaz, M.A.; Tülek, F. Composition analysis of medieval ceramics by laser-induced breakdown spectroscopy (LIBS). Appl. Phys. A Mater. Sci. Process 2016, 122, 5-10. [CrossRef]

34. López, A.J.; Nicolás, G.; Mateo, M.P.; Ramil, A.; Piñón, V.; Yáñez, A. LIPS and linear correlation analysis applied to the classification of Roman pottery Terra Sigilata. Appl. Phys. A 2006, 83, 695. [CrossRef]

35. Anzano, J.M.; Villoria, M.A.; Gornushkin, I.; Smith, B.; Winefordner, J.D. Laser-induced plasma spectroscopy for characterization of archaeological material. Can. J. Anal. Sci. Spectrosc. 2002, 47, 134-140.

36. Ferrero, A.; Lucena, P.; Herrera, R.G.; Doña, A.; Fernández-Reyes, R.; Laserna, J.J. Libraries for spectrum identification: Method of normalized coordinates versus linear correlation. Spectrochim. Acta Part B 2008, 63, 383-388. [CrossRef]

Publisher's Note: MDPI stays neutral with regard to jurisdictional claims in published maps and institutional affiliations.

(C) 2020 by the authors. Licensee MDPI, Basel, Switzerland. This article is an open access article distributed under the terms and conditions of the Creative Commons Attribution (CC BY) license (http://creativecommons.org/licenses/by/4.0/). 